\title{
Baseline nutritional status could be a predictor for radiation esophagitis in esophageal cancer patients undergoing radiotherapy
}

\author{
Jie Dong ${ }^{1 \#}$, Wencheng Zhang ${ }^{2 \#}$, Tian Zhang ${ }^{2}$, Xi Chen ${ }^{2}$, Jingjing Zhao ${ }^{2}$, Yaqi Zeng ${ }^{1}$, Yajun Chen ${ }^{1}$, \\ Xiaoying Wei ${ }^{2}$, Tongda Lei ${ }^{2}$, Ping Wang $^{2}$, Lujun $\mathrm{Zhao}^{2}$, Jun Wang ${ }^{2}$, Zhiyong Yuan ${ }^{2}$, Yongchun Song ${ }^{2}$, \\ Ningbo Liu ${ }^{2}$, Kun Wang ${ }^{1}$, Qingsong Pang ${ }^{2}$ \\ ${ }^{1}$ Department of Nutrition Therapy, ${ }^{2}$ Department of Radiation Oncology, Tianjin Medical University Cancer Institute and Hospital/National Clinical \\ Research Center for Cancer/Key Laboratory of Cancer Prevention and Therapy, Tianjin/Tianjin's Clinical Research Center for Cancer, Tianjin, \\ China \\ Contributions: (I) Conception and design: Q Pang, K Wang, W Zhang, J Dong; (II) Administrative support: P Wang, L Zhao, J Wang, Z Yuan, Y \\ Song, N Liu; (III) Provision of study materials: Y Zeng, Y Chen; (IV) Collection and assembly of data: T Zhang, X Chen, J Zhao, X Wei, T Lei; (V) \\ Data analysis and interpretation: W Zhang, J Dong; (VI) Manuscript writing: All authors; (VII) Final approval of manuscript: All authors. \\ "These authors contributed equally to this work. \\ Correspondence to: Kun Wang. Department of Nutritional Therapy, Tianjin Medical University Cancer Institute and Hospital, Huanhu West Road, \\ Hexi District, Tianjin, China. Email: tjzlyyk@126.com; Qingsong Pang. Department of Radiation Oncology, Tianjin Medical University Cancer \\ Institute and Hospital, Huanhu West Road, Hexi District, Tianjin, China. Email: pangqingsong@tjmuch.com.
}

Background: To investigate the relationship between baseline nutrition status and radiation esophagitis in patients with esophageal cancer treated by radiation therapy.

Methods: A retrospective study was performed on 100 patients with esophageal cancer who was treated with definitive chemoradiotherapy, preoperative chemoradiation and definitive radiotherapy at the Tianjin Medical University Cancer Institute and Hospital from October 2018 and October 2019. We documented the clinical characteristics of patients, including tumor location, clinical stage, treatment, radiation dose, gross tumor volume (GTV), planning tumor volume (PTV) and Atkinson's Dysphagia score (ADS), and we recorded the nutrition status before radiation, including Patient-Generated Subjective Global Assessment (PG-SGA), body mass index (BMI), weight loss percentage in 3 mouths (WL), the level of albumin (ALB), hemoglobin (HB), C-reactive protein (CRP) and Glasgow prognostic score (GPS). These factors were correlated with radiation esophagitis using univariate and multivariate regression analyses.

Results: Of 100 patients, 44\% patients with PG-SGA score $\geq 9$ at baseline, suggesting severe malnutrition, $41 \%$ patients developed grade $\geq 2$ radiation esophagitis. In univariate analysis, dose $>40 \mathrm{~Gy}(\mathrm{P}=0.015), \mathrm{PTV}$ $\geq 495 \mathrm{~cm}^{3}(\mathrm{P}=0.049), \mathrm{PG}-\mathrm{SGA}$ score $\geq 9(\mathrm{P}=0.001), \mathrm{WL} \geq 10 \%(\mathrm{P}=0.019)$ and ALB level $<35 \mathrm{~g} / \mathrm{L}(\mathrm{P}=0.043)$ were significantly associated with grade $\geq 2$ radiation esophagitis. Multivariate analysis revealed that PG-SGA score $\geq 9(\mathrm{P}=0.042)$ was the independent predictor of radiation esophagitis.

Conclusions: Baseline nutritional status associated with development of grade $\geq 2$ radiation esophagitis in patients with esophageal cancer undergoing radiotherapy.

Keywords: Esophageal cancer; nutrition; Patient-Generated Subjective Global Assessment (PG-SGA); esophagitis; radiotherapy

Submitted Feb 24, 2020. Accepted for publication Aug 19, 2020.

doi: $10.21037 / \mathrm{atm}-20-4078$

View this article at: http://dx.doi.org/10.21037/atm-20-4078 


\section{Introduction}

Esophageal cancer is often diagnosed at an advanced stage and only $30-40 \%$ patients have opportunity to surgery (1). Radiotherapy plays a crucial role in the curative management of localized esophageal cancer, both as definitive and preoperative therapy (2). Despite much progress, esophageal cancer remains difficult to treat, and the mortality rate stays persistently high, and unfortunately, all treatment approach achieve a cure rate of only $20-30 \%$. According to available date, malnutrition has been reported to be as frequent as $79 \%$ and the lose of body weight $>10 \%$ is present in more than $70 \%$ of patients with esophageal cancer before starting treatment (3). Dysphagia has been found to be the primary symptom in more than $90 \%$ patients and is the main cause of malnutrition (4). Malnutrition has been demonstrated to be associated with poor survival and increased complication in patients with cancer (5). Imultaneous occurrences of different esophageal cancer treatments contribute immensely to the development of nutrition disorders and reduce the accuracy and sensitivity of radiotherapy and decrease treatment effect. Therefore, a series of expert consensus has been achieved on the nutritional treatment of esophageal cancer international (6-8). Patients with esophageal cancer undergoing radiotherapy frequently experience radiationrelated esophagitis, which further lead to swallowing pain, long-lasting decrease intake and severe malnutrition, and ultimately affects tolerability of treatment and survival.

A growing body of literature indicated and emphasized that baseline nutrition status affects clinical response and survival for patients with esophageal cancer undergoing definitive chemoradiation or preoperative chemoradiation (9-11), and Nutritional risk index (NRI) is independent prognostic factor after definitive radiochemotherapy for esophageal cancer (12). Similarly, there was extensive literature to investigated and compared the safety and complications of different radiation doses and treatment options, including esophagitis (13-15). However, although radiation esophagitis is the primary acute toxicity during radiotherapy for esophageal cancer, few studies have reported its relationship with nutritional status.

In our study, we evaluated the nutritional status of patients with esophageal cancer who underwent radiotherapy, adopted Patient-Generated Subjective Global Assessment (PG-SGA), and recorded the occurrence of esophagitis grade $\geq 2$ and analyzed their relationship. Our results indicated that baseline PG-SGA score $\geq 9$ can be an independent risk factor for predicting radiation esophagitis grade $\geq 2$.

We present the following article in accordance with the STROBE reporting checklist (available at http://dx.doi. org/10.21037/atm-20-4078).

\section{Methods}

\section{Study population}

We retrospectively reviewed the records of 100 patients were diagnosed with a locally or inoperable nonmetastatic esophageal cancer between October 2018 and October 2019 in Tianjin Medical University Cancer Institute and Hospital. The study was conducted in accordance with the Declaration of Helsinki (as revised in 2013). The study was approved by ethics committee of Tianjin Medical University cancer institute and hospital (No. bc2020052). This study is a retrospective study and informed consent form was not required. Inclusion criteria: (I) patients included in our study had pathologically confirmed esophageal squamous cell carcinoma; (II) Karnofsky performance score (KPS) $\geq 70$; (III) age $<80$ years old; (IV) patients accepted treated by definitive concurrent chemoradiation, preoperative chemoradiation or definitive radiotherapy; (V) complete baseline nutritional status records [including percentage of weight loss (WL), body mass index (BMI), PG-SGA, GPS, Atkinson's Dysphagia score (ADS] and laboratory examinations [including prealbumin (PALB), albumin (ALB), hemoglobin (AB) and C-reactive protein (CRP)]; and the clinical assessments of patients' radiation esophagitis. Exclusion criteria: (I) patients previously received by surgery, radiotherapy or chemotherapy, or if they had distant metastasis; (II) the patient refused to accept any nutritional therapy. We divided 100 patients into two groups according to the grade of esophagitis: esophagitis grade $0-1 \quad(n=59)$ and esophagitis grade $\geq 2 \quad(n=41)$.

\section{Nutritional assessment}

Nutritional status was evaluated using the PG-SGA, a scored for quick identification malnutrition in hospitalized patients with cancer, which combines subjective (weight history, food intake, symptoms and activities, and function) and objective (diagnosis, age, metabolic stress, and physical examination) assessment of the patient. Based on the final score, the patients were categorized as well-nourished (PG-SGA A), (PG-SGA B), or severely malnourished 
(PG-SGA C) (16), assessments by a fixed professional nutritionist conducted every two weeks. The BMI was originally recognized worldwide as a grading method for assessing the degree of obesity. For Asian populations, patients are divided into the following four groups: underweight (BMI $\left.\leq 8.5 \mathrm{~kg} / \mathrm{m}^{2}\right)$; normo-weight $(18.5<\mathrm{BMI}$ $\left.\leq 23.5 \mathrm{~kg} / \mathrm{m}^{2}\right)$; overweight $\left(23.5<\mathrm{BMI}<27.5 \mathrm{~kg} / \mathrm{m}^{2}\right)$; and obese (BMI $\geq 27.5 \mathrm{~kg} / \mathrm{m}^{2}$ ) (17). Glasgow prognostic score (GPS), as an immunonutritional indices, showed great value in predicting survival outcomes of various cancer types (18-20), it combination of CRP and ALB levels, the patients were classified into GPS0 (CRP $10 \mathrm{mg} / \mathrm{L}$ and ALB $35 \mathrm{~g} / \mathrm{L}$ ), GPS1 (CRP $10 \mathrm{mg} / \mathrm{L}$ or ALB $35 \mathrm{~g} / \mathrm{L}$ ), or GPS2 (CRP $10 \mathrm{mg} / \mathrm{L}$ and ALB $35 \mathrm{~g} / \mathrm{L}$ ). Dysphagia was evaluated according to the Atkinson's classification (ADS): grade 0, ability to eat a normal diet; grade 1 , able to swallow some solid foods; grade 2, able to swallow only semi solid foods; grade 3 , able to swallow liquids only; grade 4, unable to swallow anything/total dysphagia (21).

\section{Hematological examination}

The quantity of PALB, albumin (ALB), hemoglobin (HB) and $\mathrm{C}$-reactive protein (CRP) were collected from venous blood samples at baseline and detected with an automatic blood analyzer, we collect from blood test records.

\section{Treatment plan}

\section{Radiotherapy}

IMRT radiotherapy for definitive chemoradiotherapy and definitive radiotherapy [95\% planning tumor volume (PTV) 54 Gy/30 f, 95\% PGTV 60 Gy/30 f], preoperative chemoradiation (95\% PTV 36 Gy/20 f, 95\% PGTV $40 \mathrm{~Gy} / 20 \mathrm{f}$ ), is routinely delivered once a day for five consecutive days per week, lasting for four or six weeks.

Normal organ dose constrains are as follows, the maximum dose of spinal cord is $45 \mathrm{~Gy}$; V30 of heart $<50 \%$; total lung: mean lung dose $<18 \mathrm{~Gy}, \mathrm{~V} 20<30 \%$, V $30<20 \%$, dose constrains of other specific organs are determined by the investigator.

\section{Chemotherapy}

Cisplatin $\left(25 \mathrm{mg} / \mathrm{m}^{2} / \mathrm{w}\right)$ plus docetaxel $\left(25 \mathrm{mg} / \mathrm{m}^{2} / \mathrm{w}\right)$ are administrated once per week by intravenous drip infusion for four weeks on day $1,8,15,22$ of radiotherapy.

\section{Evaluation of radiotherapy-associated esophagitis}

Grading criteria for radiation esophagitis:

(I) Asymptomatic, clinical or diagnostic observations only, intervention not indicated;

(II) Symptomatic, altered eating/swallowing, oral supplements indicated;

(III) Severely altered eating/swallowing, tube feeding, TPN or hospitalization indicated;

(IV) Life-threatening consequences; urgent operative intervention indicated: toxicity related to the treatment was evaluated using the Common Terminology Criteria for Adverse Events v4.0, toxicity assessments are performed weekly.

\section{Statistical analysis}

Statistical analyses were performed using SPSS 21.0 software (IBM SPSS Statistics, USA). The $\chi^{2}$ test was used to compare qualitative data between two groups. A univariate analysis was performed to identify the predictive factors of radiotherapy-related esophagitis ( $\mathrm{P}$ value $<0.05$ ). Multivariate analysis was performed using the logistic regression analysis with calculation of hazards ratio (HR) and a confidence interval (CI) of $95 \%$. The cut-off value of radiation dose adopted the dose of preoperative chemoradiation $40 \mathrm{~Gy}$. The best cut-off point values for gross tumor volume (GTV) and PTV were determined by receiver operating characteristic (ROC) analysis. A level of $\mathrm{P}<0.05$ was considered to be statistically significant.

\section{Results}

\section{Patient characteristics}

The total of 100 patients included in our study, the rate of esophagitis of grade $1-3$ was $69 \%$, including $28 \%$ for grade $1,34 \%$ for grade $2,7 \%$ for grade 3 , and no one for grade 4 . Table 1 compares the clinical characteristics and nutritional characteristics of the two groups (esophagitis grade $0-1$ and esophagitis $\geq$ grade 2 ). Patients in both groups had similar age (age $\geq 65: 45.8 \%$ vs. $51.2 \%$ ) and sex (male: $89.8 \%$ vs. $82.9 \%$ ) composition, and there was no statistical difference in clinical stage (III-IV: $78.0 \%$ vs. $85.4 \%$ ) and treatment (radiotherapy: chemoradiotherapy: preoperative chemoradiotherapy: $23.7 \%: 16.9 \%: 59.3 \%$ vs. $24.4 \%: 36.6 \%: 39.0 \%)$. However, 
Table 1 Patient characteristics of esophagitis grade $0-1$ and grade $\geq 2$

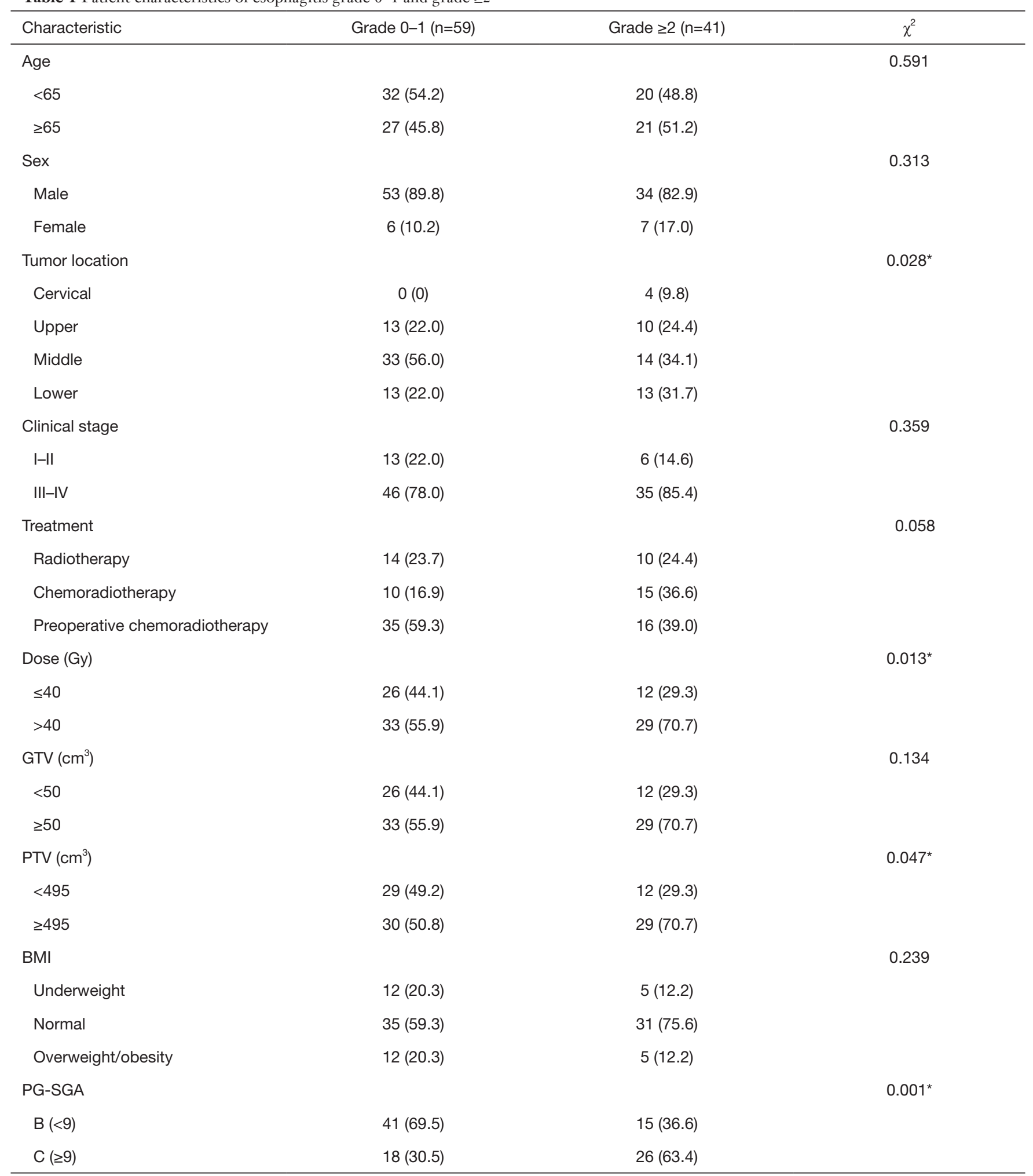

Table 1 (continued) 
Table 1 (continued)

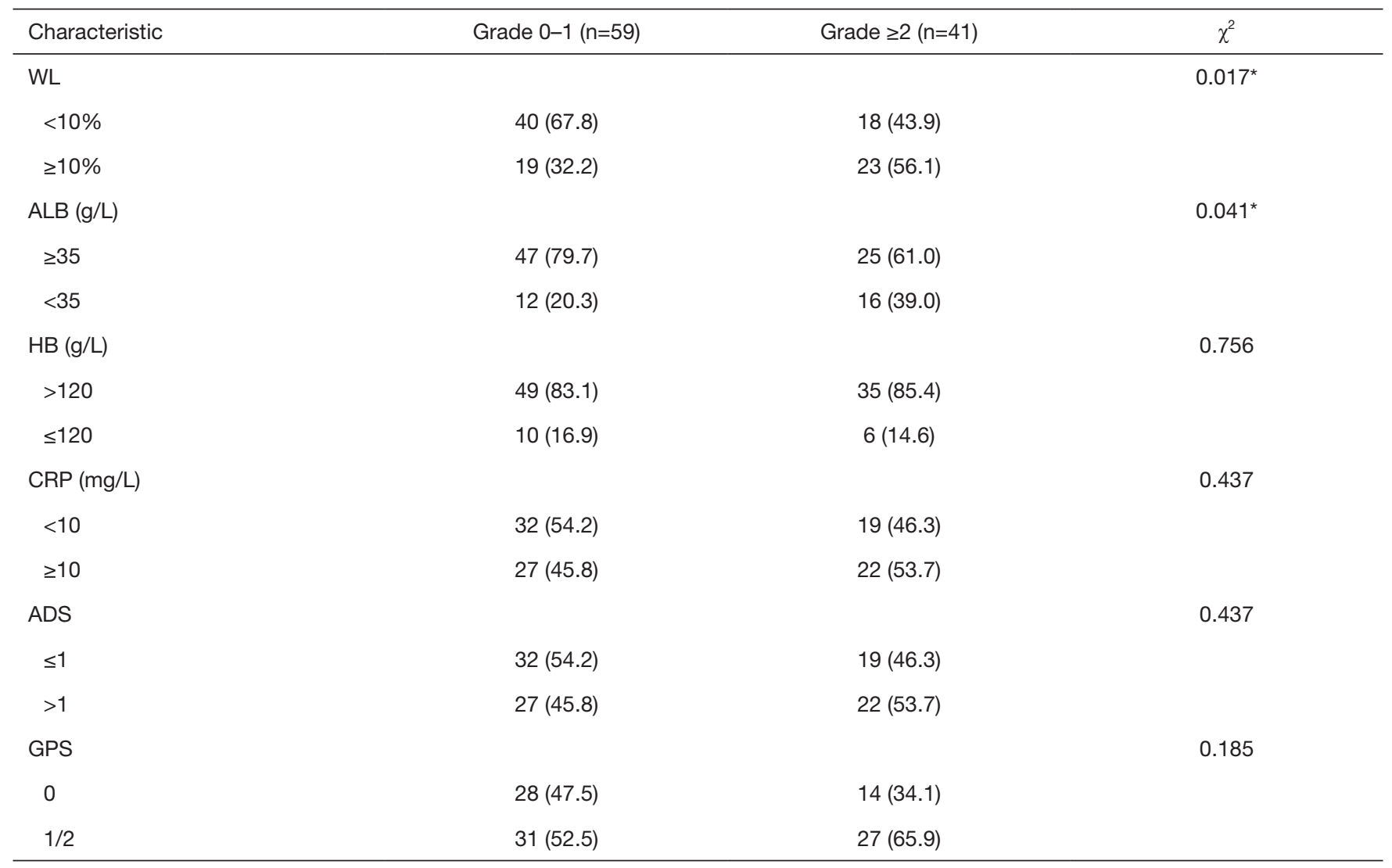

*, statistical significance at P<0.05. GTV, gross tumor volume; PTV, planning tumor volume; BMI, body mass index; PG-SGA, PatientGenerated Subjective Global Assessment; ALB, albumin; HB, hemoglobin; CRP, C-reactive protein; ADS, Atkinson dysphagia score; GPS, Glasgow prognostic score.

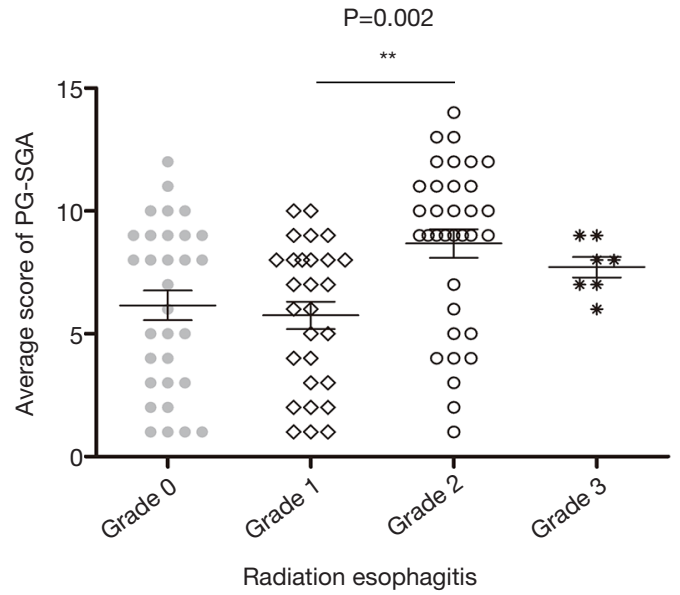

Figure 1 Average PG-SGA score of patients with different grades of radiation esophagitis. ${ }^{* *}, \mathrm{P}=0.002$. PG-SGA, Patient-Generated Subjective Global Assessment. the analysis showed that the tumor location between the two groups was statistically significant $(\mathrm{P}=0.028)$, both patients with cervical esophageal cancer developed grade $\geq 2$ esophagitis. Radiation dose and PTV were statistically different between the two groups $(\mathrm{P}=0.013, \mathrm{P}=0.047)$. In the comparison of baseline nutritional status, except for BMI, PG-SGA score $\geq 9(\mathrm{P}=0.001), \mathrm{WL} \geq 10 \%(\mathrm{P}=0.017)$ and ALB level $<35 \mathrm{~g} / \mathrm{L}(\mathrm{P}=0.041)$ were associated with the development of grade $\geq 2$ esophagitis. However, there were no statistical differences between the two groups in terms of HB, CRP, ADS and GPS. The average PGSGA score of different esophagitis grade groups is shown in Figure 1, and statistical differences in PG-SGA scores between esophagitis grade 1 and grade $2(5.75 \pm 2.95$ vs. $8.58 \pm 3.68, \mathrm{P}=0.002)$. 
Table 2 Univariate analysis of prognostic factors of esophagitis grade $\geq 2$

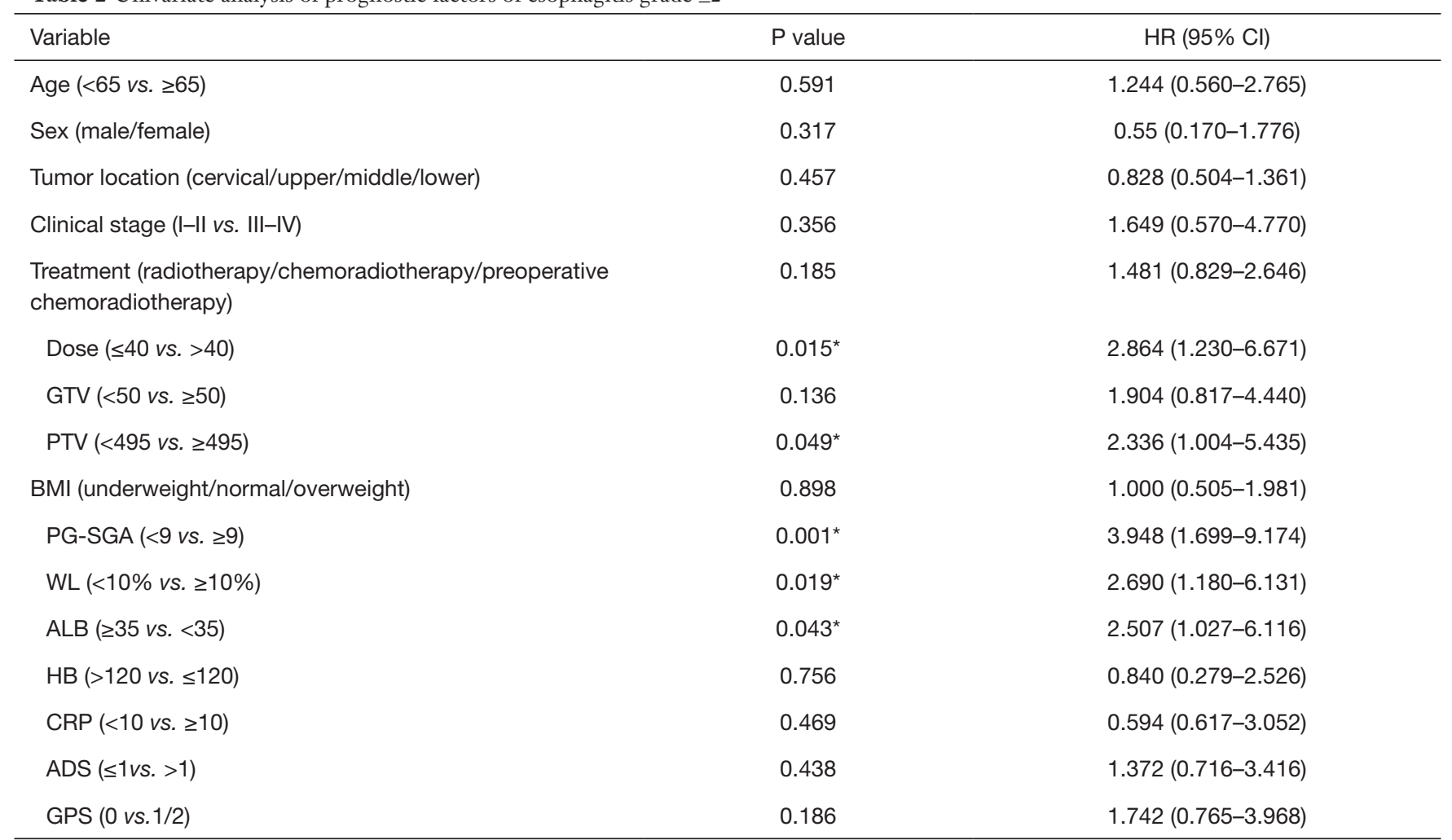

*, statistical significance at P<0.05. GTV, gross tumor volume; PTV, planning tumor volume; BMI, body mass index; PG-SGA, PatientGenerated Subjective Global Assessment; ALB, albumin; HB, hemoglobin; CRP, C-reactive protein; ADS, Atkinson dysphagia score; GPS, Glasgow prognostic score.

Table 3 Multivariate analysis of prognostic factors of esophagitis grade $\geq 2$

\begin{tabular}{lcc}
\hline & P value & $\mathrm{HR}(95 \% \mathrm{Cl})$ \\
\hline Dose $(\leq 40$ vs. $>40)$ & 0.069 & $2.109(0.929-7.328)$ \\
PTV $(<495$ vs. $\geq 495)$ & 0.227 & $1.795(0.695-4.633)$ \\
PG-SGA $(<9$ vs. $\geq 9)$ & $0.042^{*}$ & $2.641(0.998-6.991)$ \\
WL $(<10 \%$ vs. $\geq 10 \%)$ & 0.389 & $1.042(0.948-1.146)$ \\
ALB $(\geq 35$ vs. $<35)$ & 0.338 & $1.635(0.597-4.476)$ \\
\hline
\end{tabular}

*, statistical significance at P<0.05. PTV, planning tumor volume; PG-SGA, Patient-Generated Subjective Global Assessment; ALB, albumin.

\section{Univariate and multivariate analysis of prognostic factors of esophagitis grade $\geq 2$}

We performed a univariate and multivariate analysis of radiation esophagitis $\geq$ grade 2 and clinical parameters. Univariate analysis results indicated that nutritional parameters, including PG-SGA score $\geq 9(\mathrm{P}=0.001)$, WL $\geq 10 \%(\mathrm{P}=0.019)$, and ALB level $<35 \mathrm{~g} / \mathrm{L}(\mathrm{P}=0.043)$ were strongly correlated to grade $\geq 2$ radiotherapy-related esophagitis. In addition, radiation dose $>40 \mathrm{~Gy}(\mathrm{P}=0.015)$ and PTV $\geq 495 \mathrm{~cm}^{2}(\mathrm{P}=0.049)$ were also associated with the occurrence of grade $\geq 2$ esophagitis (Table 2). Multivariate analysis identified PG-SGA score $\geq 9$ was the only independent predictive factor of grade $\geq 2$ esophagitis ( $\mathrm{P}=0.042$; HR: 2.641; 95\% CI: 0.998-6.991) (Table 3). 
Table 4 Comparison of weight and biochemical nutrition parameters in patients with esophagitis grade $0-1$ and grade $\geq 2$ before and after radiotherapy

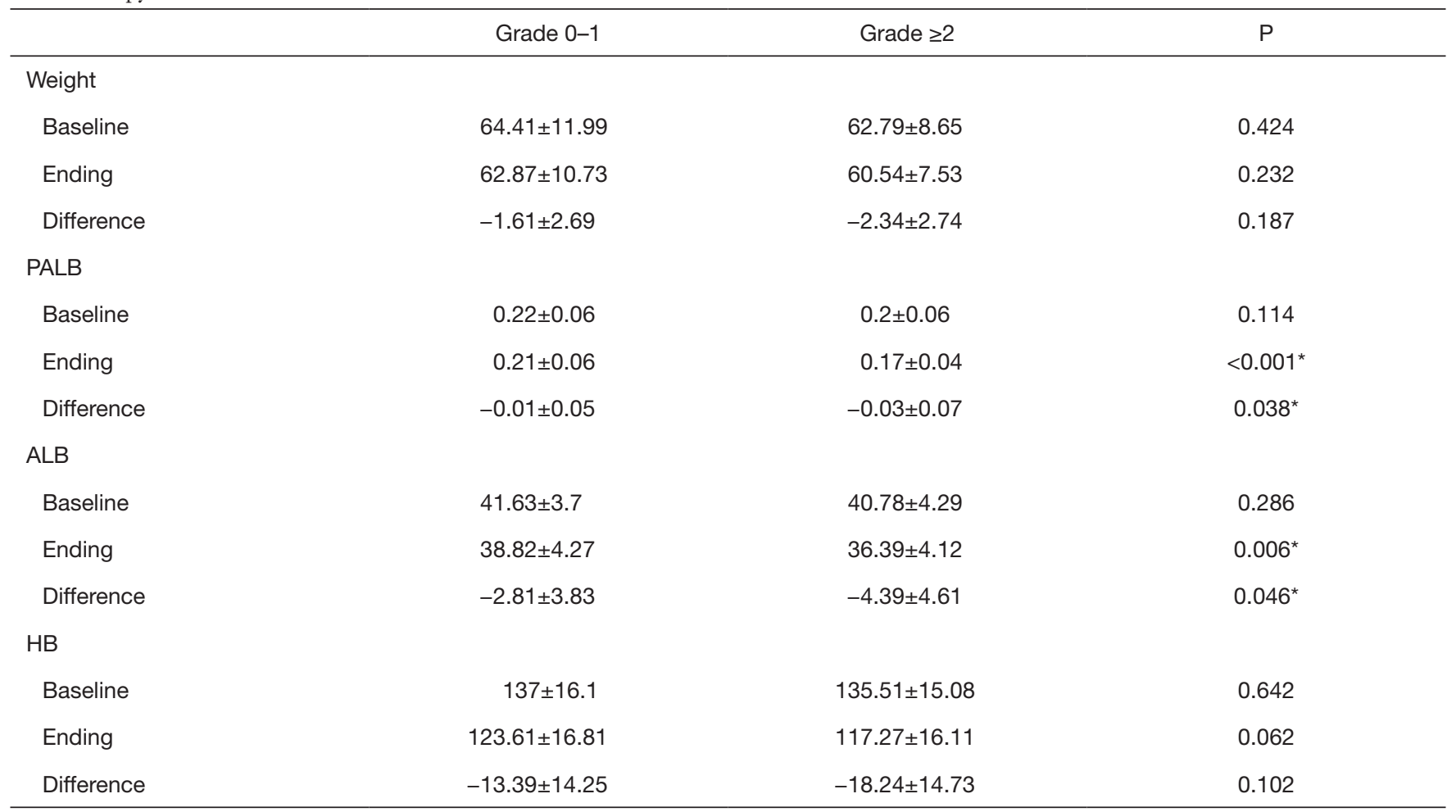

*, statistical significance at $\mathrm{P}<0.05$. PALB, prealbumin; ALB, albumin; HB, hemoglobin.

\section{Comparison of nutritional parameters before and after treatment in patients with esophagitis grade 0-1 and grade $\geq 2$}

Next, we compared the changes in weight and hematologic examination before and after treatment of patients with esophagitis grade $0-1$ group and grade $\geq 2$ group (Table 4). The analysis showed that the PALB and ALB levels were decreased at the end of radiotherapy in two groups. There was no difference in PALB and ALB levels between the two groups before treatment, however, there was a significant difference at the end of treatment $(\mathrm{P}<0.001$ and $P=0.006$ ), and the difference was statistically significant $(\mathrm{P}=0.038$ and $\mathrm{P}=0.046)$. This result suggested that patients with esophagitis grade $\geq 2$ consume more plasma ALB. Although both weight and hemoglobin also decreased at the end of treatment, the difference between the two groups was not statistically significant.

\section{Discussion}

Radiotherapy acts as an indispensable role in management of esophageal cancer (22). Radiotherapy-related esophagitis is one of the most common complications during radiotherapy in patients with esophageal cancer, and concomitant use of chemotherapeutic agents enhances this problem. Esophagitis could cause dysphagia or odynophagia, and aggravate malnutrition for patients (23). It is reported that sarcopenia caused by radiotherapy-associated esophagitis can be an independent prognostic factor for poor OS (24). There is a lot of literature confirming the relationship between radiation dose and radiation esophagitis $(13,14)$, consistently, in our univariate analysis results, there was a correlation between PTV, radiation dose and grade $\geq 2$ esophagitis, but previous articles rarely mentioned the role of baseline nutritional status in the occurrence of esophagitis. In our study, we investigated the influence of tumor location, clinical stage, treatment, radiation dose, BMI, PG-SGA score, weight loss, ALB level, hemoglobin level, CRP level, ADS and GPS score on the risk of grade $\geq 2$ esophagitis. According to our univariate and multivariate analysis results, the incidence of grade $\geq 2$ esophagitis was $41 \%$ and PG-SGA score $\geq 9$ at baseline was independently predictor of the esophagitis grade $\geq 2$.

Malnutrition is commonly reported in up to $60 \%$ to $85 \%$ 
of esophageal cancer patients before starting treatment (25). Therefore, patients with esophageal cancer are potentially at high risk of poor treatment outcomes because of preexisting malnutrition and physical deconditioning (10). Literatures indicated that baseline nutritional status can be used as a predictor of response to concurrent chemoradiotherapy and survival in patients with esophageal cancer $(9,26)$. The patient-generated-subjective global assessment (PG-SGA) was adapted from the SGA and used to define a standardized interventional approach in oncology patients (27), which combines subjective and objective assessment of the patient (changes in weight, diet, functional capacity, and physical characteristics). PG-SGA score $\geq 9$ indicates a critical need for nutrition intervention (16). In our study, $44 \%$ of patients had a PG-SGA score $\geq 9$ before radiotherapy, suggesting severe malnutrition, and $41 \%$ of patients developed grade $\geq 2$ esophagitis during treatment, and we further found that the occurrence of grade $\geq 2$ esophagitis aggravates plasma ALB consumption. Although the article suggested wholecourse nutrition management can improve the nutritional status and reduce the severity of radiation esophagitis of patients with esophageal cancer treated with concurrent chemoradiotherapy (28), our results may provide the concept basis that nutrition management may begin earlier and start antitumor treatment when nutritional status improves for patient with PG-SGA score $\geq 9$.

However, our study had several limitations. First, this study was also limited by its retrospective nature and small sample size, we are conducting a prospective clinical trial to further confirm (NCT04199832). Secondly, our study is limited to patients with esophageal squamous cell carcinoma and has no guiding significance for patients with adenocarcinoma. In addition, the formation of esophagitis is a complex process, and there may be some confounding factors that were not included in our analysis.

\section{Conclusions}

Our study first proposed the relationship between baseline nutritional status and radiation esophagitis in patients with esophageal cancer undergoing radiotherapy, and confirmed that PG-SGA can be an important predictor of grade $\geq 2$ esophagitis. Our findings suggest that nutrition intervention and management should begin before treatment, especially for patients with PG-SGA score $\geq 9$, and nutritional status should be improved before anti-tumor treatment.

\section{Acknowledgments}

Funding: This study is supported by the National Nature Science Foundation of China (No. 81872462)and the Clinical Trial Supporting Foundation of Tianjin Medical University Cancer Institute \& Hospital (Grant No. C1707).

\section{Footnote}

Reporting Checklist: The authors have completed the STROBE reporting checklist. Available at http://dx.doi. org/10.21037/atm-20-4078

Data Sharing Statement: Available at http://dx.doi. org/10.21037/atm-20-4078

Conflicts of Interest: All authors have completed the ICMJE uniform disclosure form (available at http://dx.doi. org/10.21037/atm-20-4078). The authors have no conflicts of interest to declare.

Ethical Statement: The authors are accountable for all aspects of the work in ensuring that questions related to the accuracy or integrity of any part of the work are appropriately investigated and resolved. The study was conducted in accordance with the Declaration of Helsinki (as revised in 2013). The study was approved by ethics committee of Tianjin Medical University cancer institute and hospital (No. bc2020052). This study is a retrospective study and informed consent form was not required.

Open Access Statement: This is an Open Access article distributed in accordance with the Creative Commons Attribution-NonCommercial-NoDerivs 4.0 International License (CC BY-NC-ND 4.0), which permits the noncommercial replication and distribution of the article with the strict proviso that no changes or edits are made and the original work is properly cited (including links to both the formal publication through the relevant DOI and the license). See: https://creativecommons.org/licenses/by-nc-nd/4.0/.

\section{References}

1. Jemal A, Bray F, Center MM, et al. Global cancer statistics. CA Cancer J Clin 2011;61:69-90.

2. Deng $\mathrm{W}$, Lin SH. Advances in radiotherapy for esophageal cancer. Ann Transl Med 2018;6:79. 
3. Riccardi D, Allen K. Nutritional Management of Patients With Esophageal and Esophagogastric Junction Cancer. Cancer Control 1999;6:64-72.

4. Moses FM. Squamous cell carcinoma of the esophagus. Natural history, incidence, etiology, and complications. Gastroenterol Clin North Am 1991;20:703-16.

5. Bollschweiler E, Herbold T, Plum P, et al. Prognostic relevance of nutritional status in patients with advanced esophageal cancer. Expert Rev Anticancer Ther 2013;13:275-8.

6. Chen MJ, Wu IC, Chen YJ, et al. Nutrition therapy in esophageal cancer-Consensus statement of the Gastroenterological Society of Taiwan. Dis Esophagus 2018. doi: 10.1093/dote/doy016.

7. Jordan T, Mastnak DM, Palamar N, et al. Nutritional Therapy for Patients with Esophageal Cancer. Nutr Cancer 2018;70:23-9.

8. Lyu J, Li T, Xie C, et al. Enteral nutrition in esophageal cancer patients treated with radiotherapy: a Chinese expert consensus 2018. Future Oncol 2019;15:517-31.

9. Di Fiore F, Lecleire S, Pop D, et al. Baseline nutritional status is predictive of response to treatment and survival in patients treated by definitive chemoradiotherapy for a locally advanced esophageal cancer. Am J Gastroenterol 2007;102:2557-63.

10. Song T, Wan Q, Yu W, et al. Pretreatment nutritional risk scores and performance status are prognostic factors in esophageal cancer patients treated with definitive chemoradiotherapy. Oncotarget 2017;8:98974-84.

11. Jordan T, Mastnak DM, Palamar N, et al. Nutritional Therapy for Patients with Esophageal Cancer. Nutr Cancer 2018;70:23-9.

12. Dai Y, Fu X, Li T, et al. Long-term impact of prognostic nutritional index in cervical esophageal squamous cell carcinoma patients undergoing definitive radiotherapy. Ann Transl Med 2019;7:175.

13. Ren X, Wang L, Han C, et al. Retrospective analysis of safety profile of high-dose concurrent chemoradiotherapy for patients with oesophageal squamous cell carcinoma. Radiother Oncol 2018;129:293-9.

14. Song T, Liang X, Fang M, et al. High-dose versus conventional-dose irradiation in cisplatin-based definitive concurrent chemoradiotherapy for esophageal cancer: a systematic review and pooled analysis. Expert Rev Anticancer Ther 2015;15:1157-69.

15. Sasaki Y, Kato K. Chemoradiotherapy for esophageal squamous cell cancer. Jpn J Clin Oncol 2016;46:805-10.

16. Bauer J, Capra S, Ferguson M. Use of the scored PatientGenerated Subjective Global Assessment (PG-SGA) as a nutrition assessment tool in patients with cancer. Eur J Clin Nutr 2002;56:779-85.

17. Consultation WHOE. Appropriate body-mass index for Asian populations and its implications for policy and intervention strategies. Lancet 2004;363:157-63.

18. Nozoe T, Matono R, Ijichi H, et al. Glasgow Prognostic Score (GPS) can be a useful indicator to determine prognosis of patients with colorectal carcinoma. Int Surg 2014;99:512-7.

19. Zhu J, Wang H, Liu CC, et al. The Glasgow Prognostic Score (GPS) is a novel prognostic indicator in advanced epithelial ovarian cancer: a multicenter retrospective study. J Cancer Res Clin Oncol 2016;142:2339-45.

20. Omichi C, Nakamura K, Haraga J, et al. Glasgow prognostic score is an independent marker for poor prognosis with all cases of epithelial ovarian cancer. Cancer Med 2016;5:1074-80.

21. Ogilvie AL, Dronfield MW, Ferguson R, et al. Palliative intubation of oesophagogastric neoplasms at fibreoptic endoscopy. Gut 1982;23:1060-7.

22. Deng $\mathrm{W}$, Lin $\mathrm{SH}$. Advances in radiotherapy for esophageal cancer. Ann Transl Med 2018;6:79.

23. Chowhan NM. Injurious effects of radiation on the esophagus. Am J Gastroenterol 1990;85:115-20.

24. Ma DW, Cho Y, Jeon MJ, et al. Relationship Between Sarcopenia and Prognosis in Patient With Concurrent Chemo-Radiation Therapy for Esophageal Cancer. Front Oncol 2019;9:366.

25. Mariette C, De Botton ML, Piessen G. Surgery in esophageal and gastric cancer patients: what is the role for nutrition support in your daily practice? Ann Surg Oncol 2012;19:2128-34.

26. Clavier JB, Antoni D, Atlani D, et al. Baseline nutritional status is prognostic factor after definitive radiochemotherapy for esophageal cancer. Dis Esophagus 2014;27:560-7.

27. Ottery FD. Definition of standardized nutritional assessment and interventional pathways in oncology. Nutrition 1996;12:S15-9.

28. Qiu Y, You J, Wang K, et al. Effect of whole-course nutrition management on patients with esophageal cancer undergoing concurrent chemoradiotherapy: A randomized control trial. Nutrition 2020;69:110558.

Cite this article as: Dong $\mathrm{J}$, Zhang $\mathrm{W}$, Zhang $\mathrm{T}$, Chen $\mathrm{X}$, Zhao J, Zeng Y, Chen Y, Wei X, Lei T, Wang P, Zhao L, Wang J, Yuan Z, Song Y, Liu N, Wang K, Pang Q. Baseline nutritional status could be a predictor for radiation esophagitis in esophageal cancer patients undergoing radiotherapy. Ann Transl Med 2020;8(18):1148. doi: 10.21037/atm-20-4078 